\title{
Modeling to Study the Effect of Environmental Parameters on Corrosion of Mild Steel in Seawater Using Neural Network
}

\author{
Subir Paul \\ Department of Metallurgical and Material Engineering, Jadavpur University, Kolkata 700032, India \\ Correspondence should be addressed to Subir Paul, spaulxx@ymail.com \\ Received 15 December 2011; Accepted 4 January 2012 \\ Academic Editors: J. Eckert and J. M. Rodriguez-Ibabe \\ Copyright () 2012 Subir Paul. This is an open access article distributed under the Creative Commons Attribution License, which \\ permits unrestricted use, distribution, and reproduction in any medium, provided the original work is properly cited. \\ Prediction of corrosion rate of steel structure in seawater is a challenging task for design and corrosion engineers for existing as \\ well as new structures, due to wide variation of its composition across the global marine environment. The major parameters \\ influencing the rate are salinity, sulphate, dissolved oxygen, $\mathrm{pH}$, and temperature. While the individual effects of these parameters \\ on corrosion are known, the conjoint effect of the parameters together is complex and unpredictable. Endeavors have been made \\ to model the corrosion rate from laboratory experimental data, using Artificial Neural Network to predict corrosion rate at any \\ combinations of the above five parameters and to better understand the effects of these parameters jointly on corrosion behavior. \\ 3D mappings clearly reveal the complex interrelationship between the variables and importance of conjoint effect of the variables \\ rather than single variable on the corrosion rate of steel in seawater.
}

\section{Introduction}

Prediction of corrosion rate of steel structure in global marine environment is a challenging task due to wide variation of parameters controlling the rate. The chloride $\left(\mathrm{Cl}^{-}\right)$ concentration of seawater varies from about $5.8 \mathrm{gm} / \mathrm{Kg}$ to about $24 \mathrm{~g} / \mathrm{Kg}$, the sulphate $\left(\mathrm{SO}_{4}^{2-}\right)$ from $0.8 \mathrm{gm} / \mathrm{Kg}$ to $3.4 \mathrm{gm} / \mathrm{Kg}$ and the bicarbonate $\left(\mathrm{HCO}_{3}^{-}\right)$from $0.01 \mathrm{gm} / \mathrm{Kg}$ to $0.2 \mathrm{gm} / \mathrm{Kg}[1]$, across the different ocean and sea water. Though the $\mathrm{pH}$ of sea water is in the range of neutral to slightly alkaline, local acidity developed due to corrosion products as well as crude petroleum products, lowering the $\mathrm{pH}$ to around 4. In general the influence of any of the five parameters, namely, salinity, sulphate, dissolved oxygen, $\mathrm{pH}$, and temperature, on corrosion rate, is independently known. Chloride ion aggravates the degradation of materials in aqueous environment. It helps in breaking passive oxide layer, leading to localized corrosion of crevice and pitting corrosion. $\mathrm{PH}$ has a variable effect on corrosion. Corrosion rate is high at lower $\mathrm{pH}$ due to acidic corrosion, while, at intermediate $\mathrm{pH}$ of 8.5 to 12 , it drops down due to formation of passive layer and, at higher $\mathrm{pH}$, the corrosion is severe due to caustic embrittlement. Sulphate ion in general helps the formation of corrosion resistant deposit with $\mathrm{Ca}$ and $\mathrm{Mg}$ ions, but at lower $\mathrm{pH}$ this deposit goes in solution and corrosion rate is enhanced. Both temperature and dissolved oxygen have a strong effect of increasing the corrosion rate due to the fact that the concentration of dissolved oxygen increases the rate of cathodic reaction of water reduction and also the limiting current density of concentration polarization. Temperature increases the diffusion rates of the ions and helps in convection mass transfer, both of which promote depolarization. But conjoint effect of the abovementioned parameters and the interrelationship among the variables on corrosion rate are complex and not known.

Modeling helps better understanding of corrosion process and the effect of conjoint actions of parameters which are unknown and non-linear functions of the rate. It also helps the construction and corrosion engineers by predicting the life of the structure in a given environment. Complexity of the present problem, involving the effect of the five parameters on single output, necessitates the modeling by artificial neural networks (NNs). It is one of the most powerful modeling techniques based on statistical approach. The method of neural-network simulation is applicable to the corrosion processes as the multifactor systems represented 
by an aggregate of corrosion-electrochemical parameters (the characteristic potentials and currents are not cymbatical to the parameters of medium, the anionic composition, concentration, temperature, $\mathrm{pH}$ value, etc.). This would enable us to reveal the hidden links, which are difficult to analyze.

In the past few years, there has been a constantly increasing interest for $\mathrm{NN}$ modeling in different fields of materials science. ANN models have been developed to model different correlations and phenomena in steels [2-5], aluminum alloys [6] and titanium alloys $[7,8]$. There has been only limited work on the application of neural network on the effect of the variables influencing marine corrosion process $[9,10]$.

\section{Modeling Methodology}

An ANN algorithm [11-14] of studying systems involves a set of uniform modules, named associative neurons. Each of them has a certain number of information inputs, which are equal to the number of independent input parameters of the system, and a certain number of outputs, where the output parameters are formed. The output parameter is calculated by substituting a set of input parameters into a certain function (identical for all of associative neurons of network) taking into account the corresponding set of weight coefficients. The advantage of $\mathrm{NN}$ as a tool for the analysis of experimental data is, primarily, its capability of learning, that is, forming the ability to predict the output parameters of a system by any set of input ones. Usually, neural networks are trained using a large number of input with corresponding output data (input/output pairs) so that a particular set of inputs produces, as nearly as possible, a specific set of target outputs, by adjusting the weight associated with each connection (synapse) between neurons. NNs are capable of generalizing experience obtained in the course of learning. As a result, it becomes possible to predict the situations, which are absent in the set of experimental results.

The following matters are important in the design and training of neural networks: (i) architecture of the neural network, (ii) training algorithm, and (iii) transfer function. The term "architecture of the neural network" refers to the number of the layers in the $\mathrm{NN}$ and the number of the neurons in each layer. The general structure of input, one hidden and one output layer was used. The numbers of neurons in the input layer and the output layer are determined by the numbers of input and output parameters, respectively. In order to find the optimal architecture, different numbers of neurons in the hidden layer were attempted.

There are many different training algorithms. The details for the NN training algorithms are given in [13]. In order to achieve the best result, different training algorithms were attempted including Batch Gradient Descent, Batch Gradient Descent with Momentum, One-step-secant, Scaled Conjugate Gradient, Resilient Backpropagation, Variable Learning Rate, and Levenberg-Marquardt.

Different training options have been carried out including training on variations of mean square error for better generalization, training against a validation set, and training until the gradient of the error reaches a minimum. Improvement of the generalization has been attempted by means of "regularization" and "early stopping with validation." The transfer function transforms the neuron input value into the output value. For all cases, NN linear transfer function was used in the output layers. In the hidden layers tansigmoid transfer function and log-sigmoid transfer function were employed.

All neural network models were tested by (i) linear regression between $\mathrm{NN}$ predictions and new experimental data, (ii) statistical analysis of the error of $\mathrm{NN}$ predictions, and (iii) direct comparison of NN predicted and experimental data.

Five input neurons, namely, salinity, sulphate, dissolved oxygen, $\mathrm{pH}$, and temperature, were taken to predict output, the corrosion current. The number of sets of laboratory experimental data (87) was divided as $60 \%$ for training, $20 \%$ for testing, and the rest $20 \%$ for validation. Very good performances of the models are achieved. The neural network models are used for further simulations and predictions at various combinations of input.

\section{Experimental Procedure}

Series of laboratory experiments were performed to produce the data of corrosion rate for training, testing, and validation of neural network. Rectangular samples of $1 \times 2 \mathrm{~cm}^{2}$ were cut from the mild steel bar. They were ground carefully in order to make the edges blunt. The samples were then further ground by belt drive and polished up to $3 / 0$ emery paper. The samples were washed with acetone and were observed under a low-magnification microscope to inspect for any surface defect of pit or scratch. Fresh solutions were prepared before each experiment, using $\mathrm{KCl}, \mathrm{CaCl}_{2}, \mathrm{NaHCO}_{3}$, and $\mathrm{MgSO}_{4}$ salts in double-distilled water with variation of five experimental variables: salinity, sulphate, dissolved oxygen, $\mathrm{pH}$, and temperature. Polarization experiments were carried out as per ASTM standard methods [15-19] using Gamry Potentiostat. Standard Corrosion Cell has been used to perform the electrochemical potentiostatic polarization tests using Gamry Potentiostat. Corrosion rates were determined by Tafel's extrapolation and linear polarization methods, with repetitions of experiments under same conditions for at least thrice till the consistency of the results are obtained.

\section{Results and Discussions}

The architecture of the neural networks (NNs) is multiplayer perceptron with (1) the layer of neurons receptors (the input layer) realizing a receipt of information from the outside, (2) the layer of associative neurons (hidden), whose functions were chosen, and (3) the layer of output neurons, which form the response of the network to the external stimulus. An ANN of such a type is termed perceptron with one hidden layer of neurons. Most of applied works are associated with the use of such networks, because they are best studied and as a rule, one hidden layer is sufficient to solve the 


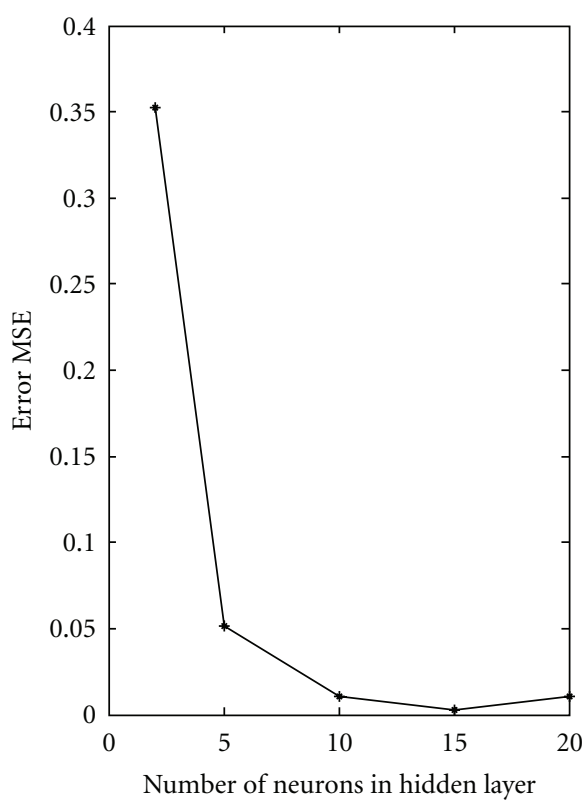

(a)

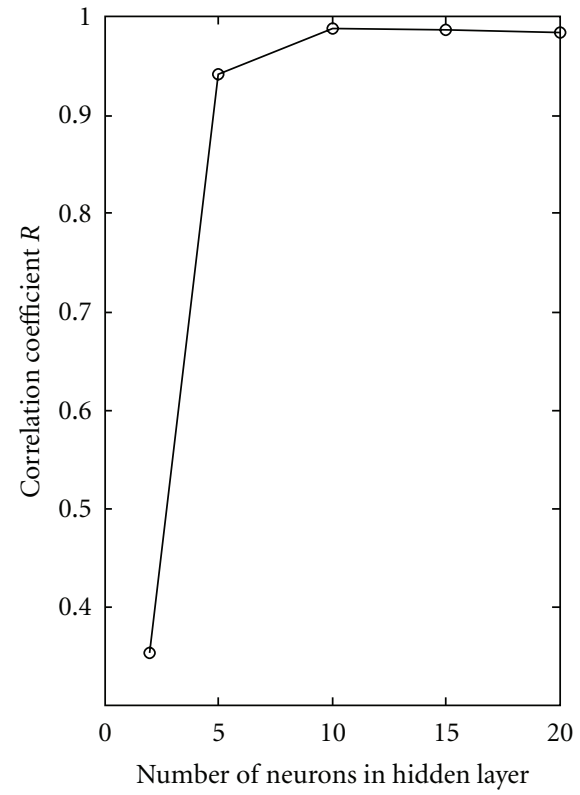

(b)

FIGURE 1: Effect of neuron size on performance of neural network.

majority of problems $[1,5,7]$. The input layer consists of five input variables of chloride, sulphate, dissolved oxygen, $\mathrm{pH}$, and temperature of the seawater. The output layer is of single output of corrosion current density. Feedforward backpropagation algorithm was used for network training with transfer functions of tan-sigmoid (tansig) and purelin for hidden and output layers, respectively. The network was trained with Batch Gradient Descent (traingd). The selection of above transfer functions and training function are based on the fact that these combinations of functions with the present experimental data give minimum error. To choose an optimum number of neurons in the hidden layer, different numbers of neurons were selected and the errors MSE were compared (Figure 1). It is found that an optimum number of 15 neurons in the hidden layer gives the minimum error. Using the above architect of the NNs, it was trained. The performance of training, testing and validation has been illustrated in Figure 2. It is seen after about 50 epoch, validation and test lines almost merge with each other. The training curve meets the goal of threshold error of 0.002 after 375 epochs. The result indicates a good performance of training. The outputs of corrosion current obtained from the model were compared with those from experimental determined data to validate the model, and a regression line of near $45^{\circ}$ was obtained (Figure 3 ) with correlation coefficient $R$ of 0.98968 . This signifies the network has been well trained and the prediction of corrosion rate by the model can very well match with that of actual experimental determination.

Every model has some limitations and uncertainty. In neural network, a huge number. of experimental data is required; the more the data, the better the simulation and prediction. Out of these data, about $60 \%$ are used for

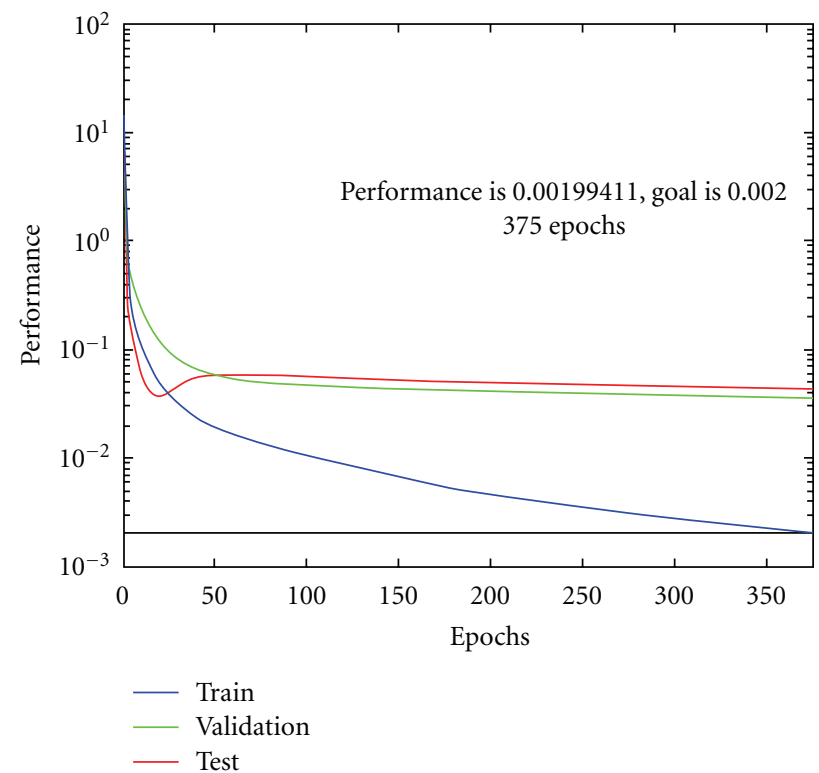

FIGURE 2: Training of neural network with corrosion rate data of mild steel using traingd as training function, Tansig and purlin as transfer functions.

studying the trend (training) and developing the initial model. It now tests model on another new set of data $(20 \%)$; if the test performance (the level to be indicated by the user) is not satisfactory, it then goes back and redevelops the model. When the test is satisfied, it takes another new set of data (balance 20\%) and simulates or predicts the unknown and compares its simulated results with actual (experimental or field data), if it is satisfactory, the final model is generated; 


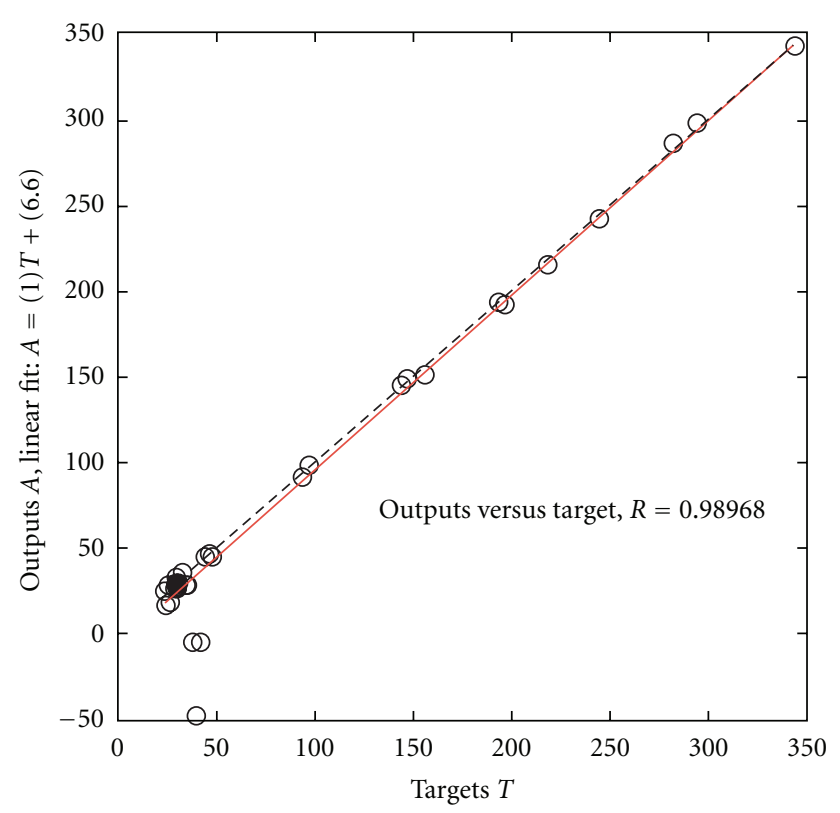

Data points
- Best linear fit
$---A=T$

Figure 3: Regression line between output generated from the model and target of corrosion data obtained from experiments.

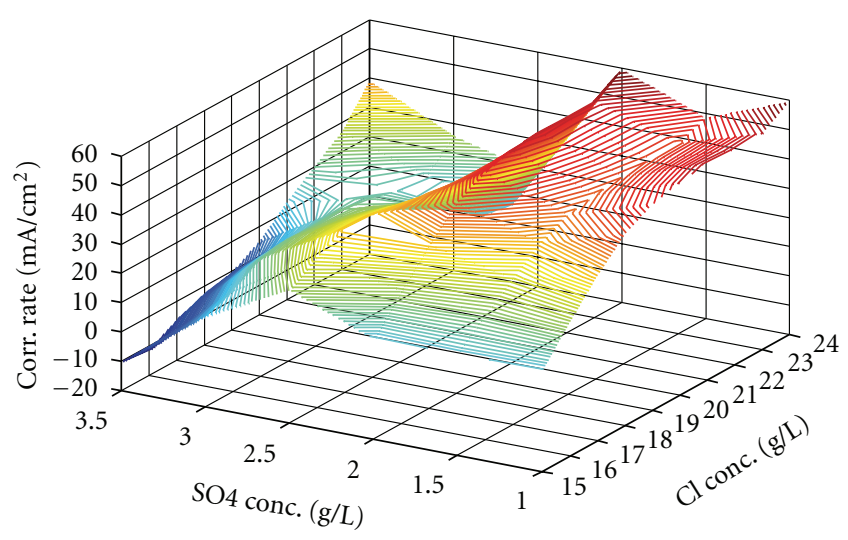

FIGURE 4: Corrosion behavior of MS in seawater with variation of $\mathrm{Cl}$ and $\mathrm{SO}_{4}$ conc. at $\mathrm{pH} 8$.

if not it goes back to the first step. So under so many steps of training, testing and validation, it has been found that the neural network can be very accurately predicted in most cases subject to the accuracy of experimental data and large number of data, covering full domain of the parameters variables.

The model is now used to simulate the unknown corrosion rates at any combinations of the five parameters to study the corrosion behavior of steel in any global marine environment. It also helps to find the corrosion rate of steel structure at a given geographical site in an ocean.
Figure 4 shows the effects of chloride and sulphate ion concentrations on the corrosion rate of mild steel in seawater. It is seen that, while the chloride ion aggravates the corrosion rate, the sulphate ion has marginal effect at lower concentration and decreases the rate sharply at higher concentration. This is due to the fact that the presence of sulphate ion helps in formation of calcareous deposit in alkaline region, with presence of $\mathrm{Ca}$ and $\mathrm{Mg}$ ions. Sulphate ions have an important role during calcareous deposition on a steel; they promote the formation of the $\mathrm{Mg}$-containing porous layer. In seawater, the $\mathrm{Mg}$-containing film forming on steel would then be $\mathrm{Mg}$ basic sulphate, $x \mathrm{Mg}(\mathrm{OH})_{2} \cdot \mathrm{MgSO}_{4}$. $n \mathrm{H}_{2} \mathrm{O}[20]$. Secondly sulphate ions had participated directly to the corrosion process of iron in seawater by promoting the formation of an intermediate Fe(II-III) hydroxysulphate $[21,22]$ of the Green Rust by the following reactions:

$6 \mathrm{Fe}^{2+}+12 \mathrm{H}_{2} \mathrm{O}+\mathrm{SO}_{4}{ }^{2-} \longleftrightarrow \mathrm{Fe}_{4}{ }_{4} \mathrm{Fe}^{\mathrm{III}}{ }_{2}(\mathrm{OH})_{12} \mathrm{SO}_{4}+12 \mathrm{H}^{+}+2 \mathrm{e}$

It is interesting to find that the corrosion rate enhances when both sulphate and chloride concentrations are very high. The effects of $\mathrm{pH}$ and chloride on corrosion rate have been illustrated in Figure 5. At higher level of chloride concentration, the variation of $\mathrm{pH}$ from 4 to 8 does not reflect much effect on corrosion rate. At lower level of $\mathrm{Cl}^{-}$ ions, the corrosion rate decreases at near neutral to alkaline region of the medium. Figure 6 is an interesting diagram of the conjoint effect of $\mathrm{pH}$ and sulphate at fixed chloride concentration. The corrosion surface shows a minima at near neutral $\mathrm{pH}$ and high sulphate concentration. The rate increases with acidity or alkalinity in seawater. The diagram clearly indicates the complex interrelationship that exits between the variables and the importance of conjoint effect of variables rather than with single variable. $\mathrm{SO}_{4}^{2-}$ ions seem to help in the formation of corrosion resistant deposit in near neutral seawater. The effects of temperature and dissolved oxygen content on corrosion rate have been illustrated in Figure 7. While both of the parameters aggravate the corrosion rate, the effect of temperature is pronounced only when appreciable amount of dissolved oxygen is present in seawater and vice versa. The electrochemical corrosion of carbon steel in aqueous environment like seawater takes place by the following anodic and cathodic reactions:

$$
\begin{gathered}
2 \mathrm{Fe} \longrightarrow 2 \mathrm{Fe}^{2+}+4 \mathrm{e} \text { Anodic } \\
\mathrm{O}_{2}+2 \mathrm{H}_{2} \mathrm{O}+4 \mathrm{e} \longrightarrow 4 \mathrm{OH}^{-} \text {Cathodic }
\end{gathered}
$$

It is seen that the concentration of dissolved oxygen $\mathrm{O}_{2}$ enhances the rate of cathodic reaction. It is known from the polarization diagram of low carbon steel in aerated aqueous environment [23] that the anodic line cuts at concentration polarization region of the cathodic polarization curve at $E_{\text {corr }}-I_{\text {corr }}$ point. The rate of cathodic reaction is controlled by $I_{L}$, the limiting current density, which is a strong function of concentration and diffusion of oxygen from the bulk solution to the interface. This explains the enhancement of the corrosion rate with increase of dissolved oxygen concentration. The limiting current density is also very 


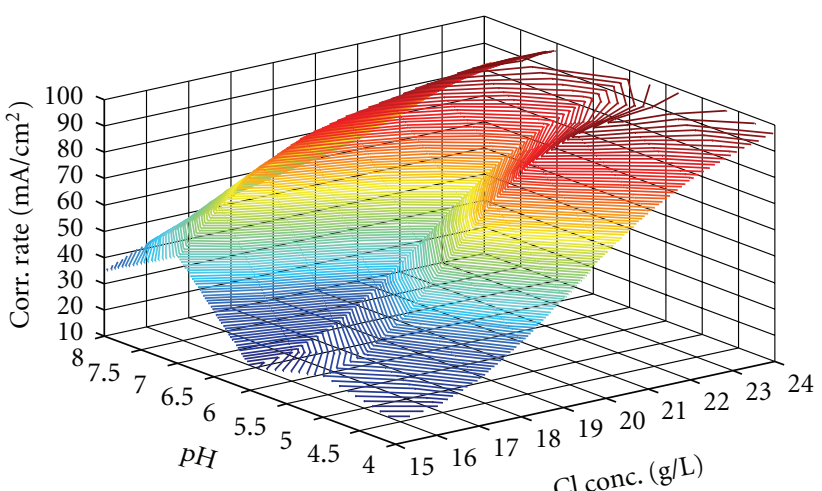

FIGURE 5: Corrosion behavior of MS in seawater with variation of $\mathrm{Cl}$ and $\mathrm{pH}$ at $\mathrm{SO}_{4}$ conc. of $2 \mathrm{~g} / \mathrm{L}$.

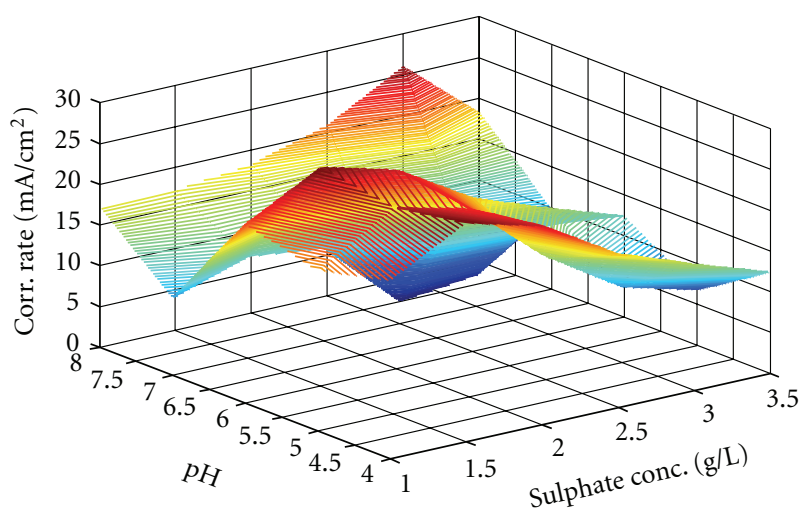

FIGURE 6: Corrosion behavior of MS in seawater with variation of $\mathrm{pH}$ and $\mathrm{SO}_{4}$ at $\mathrm{Cl}$ conc. of $15 \mathrm{~g} / \mathrm{L}$.

much influenced by the temperature, which enhances the corrosion rate. Figure 8 shows the conjoint effect of dissolved oxygen and chloride concentration on corrosion rate. It is seen while both the parameters aggravate corrosion rate, the effect of chloride ion in enhancing corrosion rate is higher. The dissolved oxygen influences the cathodic reaction and the chloride ion controls the anodic reaction. Chloride ion increases the rate of 1st reaction (anodic) by forming metal chloride, which hydrolyzes to generate $\mathrm{H}^{+}$ions, increasing the local acidity that aggravates further the dissolution process. It is interesting to note from Figure 8 that at high chloride concentration and dissolved oxygen content, the corrosion rate is less than that at lower dissolved oxygen content. This might be due to the fact that excess oxygen can now act on anodic areas also and may form protective oxide layer, retarding the attack of chloride ion on anodic sites.

\section{Conclusion}

Effect of seawater parameters on corrosion rate of steel is very well studied by modeling with neural network. It is found from the $3 \mathrm{D}$ mapping that the corrosion rate is a complex non-linear function of the variables. Influence of one parameter on the rate is much dependent on concentration of other

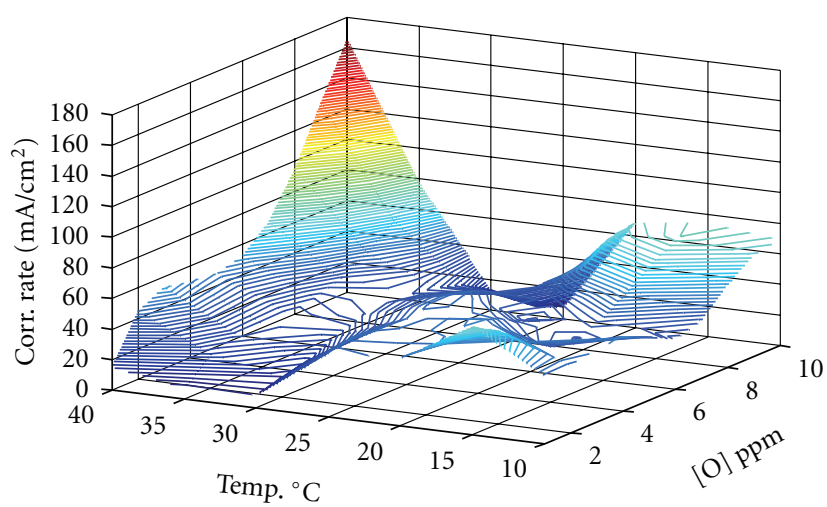

Figure 7: Corrosion behavior of MS in seawater with variation of temperature and dissolved Oxygen at $\mathrm{Cl}$ conc. of $15 \mathrm{~g} / \mathrm{L}$.

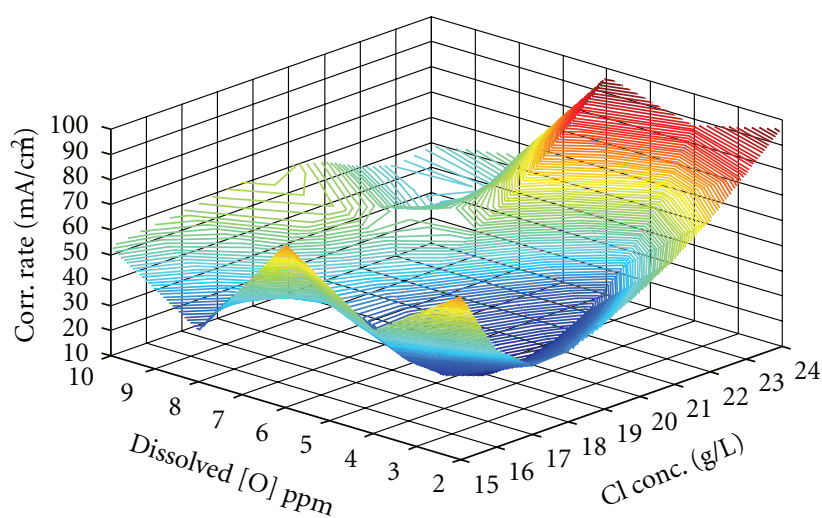

FIGURE 8: Corrosion behavior of MS in seawater with variation of dissolved oxygen and chloride.

variable. While the chloride ion increases the corrosion rate, the sulphate ion decreases corrosion rate by helping to form calcareous deposit. This fact is dependent on the level of $\mathrm{pH}$. At lower level of $\mathrm{Cl}^{-}$ions, the corrosion rate decreases at near neutral to alkaline region of the medium. Temperature and dissolved oxygen, both parameters, aggravate the corrosion rate; the effect of temperature is pronounced only when appreciable amount of dissolved oxygen is present in seawater and vice versa. The model can predict the corrosion rate of steel structure at any location site of the ocean.

\section{References}

[1] Dechema Handbook of Corrosion, vol. 11, VCH Publishers, Weinheim, NY, USA, 1992.

[2] M. A. Yescas, H. K. D. H. Bhadeshia, and D. J. MacKay, "Estimation of the amount of retained austenite in austempered ductile irons using neural networks," Materials Science and Engineering A, vol. 311, no. 1-2, pp. 162-173, 2001.

[3] E. A. Metzbower, J. J. DeLoach, S. H. Lalam, and H. K. D. H. Bhadeshia, "Neural network analysis of strength and ductility of welding alloys for high strength low alloy shipbuilding steels," Science and Technology of Welding and Joining, vol. 6, no. 2, pp. 116-124, 2001. 
[4] S. Malinov, W. Sha, and Z. Guo, "Artificial neural network modelling of crystallization temperatures of the Ni-P based amorphous alloys Material," Materials Science and Engineering A, vol. 283, pp. 1-218, 2000.

[5] S. Malinov, W. Sha, and J. J. McKeown, "Modelling the correlation between processing parameters and properties in titanium alloys using artificial neural network," Computational Materials Science, vol. 21, no. 3, pp. 375-394, 2001.

[6] O. Gundersen, A. O. Kluken, O. R. Myhr et al., Mathematical Modeling of Weld Phenomena 5, Edited by H. Cerjak, Institute of Materials, London, UK, 2001.

[7] S. McShane, S. Malinov, J. J. McKeown, and W. Sha, Computational Modeling of Materials, Minerals, and Metals Processing, Edited by M. Cross, J.W. Evans, C. Bailey, TMS, Easton, Pa, USA, 2001.

[8] S. Malinov and W. Sha, "Application of artificial neural networks for modelling correlations in titanium alloys," Materials Science and Engineering A, vol. 365, no. 1-2, pp. 202-211, 2004.

[9] V. D. Kiselev, S. M. Ukhlovtsev, A. N. Podobaev, and I. I. Reformatskaya, "Analysis of corrosion behavior of steel 3 in chloride solutions by using neural networks," Protection of Metals, vol. 42, no. 5, pp. 452-458, 2006.

[10] K. V. S. Ramana, T. Anita, S. Mandal et al., "Effect of different environmental parameters on pitting behavior of AISI type 316L stainless steel: experimental studies and neural network modeling," Materials and Design, vol. 30, no. 9, pp. 3770-3775, 2009.

[11] F. Yosserman, Neirokomp'yuternaya tekhnika: Teoriya I Praktika (Neural-Computer Technique: Theory and Practice), Mir, Moscow, Russia, 1992.

[12] A. N. Gorban, Obuchenie neironnykh setei (Learning of Neural Networks), SP ParaGraf, Moscow, Russia, 1991.

[13] K. Gurney, An Introduction to Neural Network, UCL Press Limited, 1997.

[14] L. Ileană, C. Rotar, and A. Incze, "The optimization of feed forward neural network structures using genetic algorithm," in Proceedings of the International Conference on Theory and Applications of Mathematics and Informatics (ICTAMI '04), Thessaloniki, Greece, 2004.

[15] J. R. Scully, "Polarization resistance method for determination of instantaneous corrosion rates," Corrosion, vol. 56, no. 2, pp. 199-217, 2000.

[16] ASTM G 5, Potentiostatic and Potentiodynamic Anodic Polarization Measurements.

[17] ASTM G 59, Polarization Resistance Measurements.

[18] ASTMG 61, Cyclic Polarization Measurements for Localized Corrosion.

[19] N. G. Thompson and J. H. Payer, DC Electrochemical Test Methods, National Association of Corrosion Engineers, Houston, Tex, USA.

[20] C. Barchiche, C. Deslouis, O. Gil, S. Joiret, P. Refait, and B. Tribollet, "Role of sulphate ions on the formation of calcareous deposits on steel in artificial seawater; the formation of Green Rust compounds during cathodic protection," Electrochimica Acta, vol. 54, no. 13, pp. 3580-3588, 2009.

[21] Ph. Refait, J. B. Memet, C. Bon, R. Sabot, and J. M. R. Génin, "Formation of the $\mathrm{Fe}(\mathrm{II})-\mathrm{Fe}(\mathrm{III})$ hydroxysulphate green rust during marine corrosion of steel," Corrosion Science, vol. 45, no. 4, pp. 833-845, 2003.

[22] S. Pineau, R. Sabot, L. Quillet et al., "Formation of the Fe(IIIII) hydroxysulphate green rust during marine corrosion of steel associated to molecular detection of dissimilatory sulphite-reductase," Corrosion Science, vol. 50, no. 4, pp. 10991111, 2008.
[23] D. A. Jones, Principles and Prevention of Corrosion, Prentice Hall, 2nd edition, 1996. 

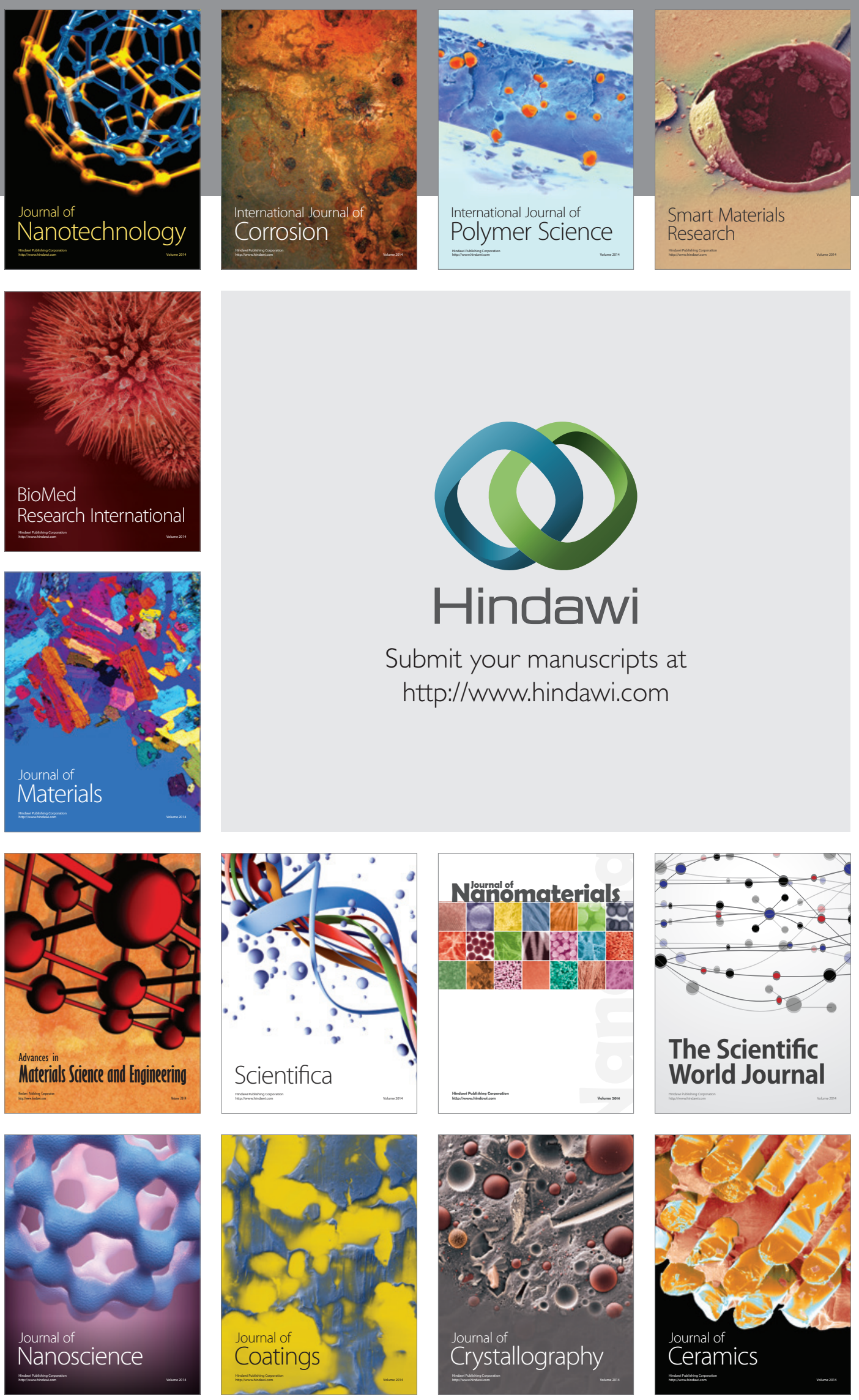

The Scientific World Journal

Submit your manuscripts at

http://www.hindawi.com

\section{World Journal}

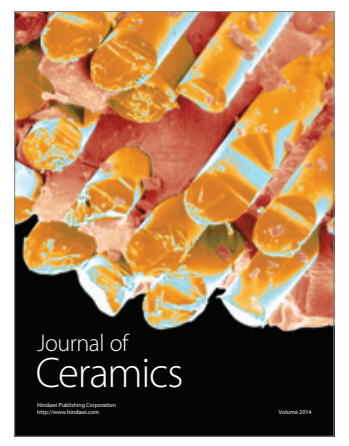

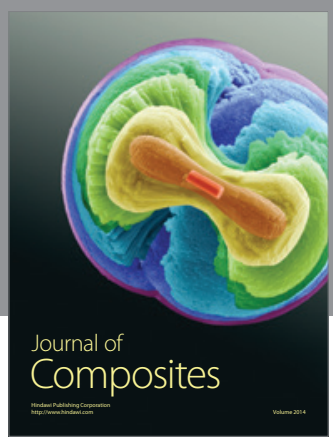
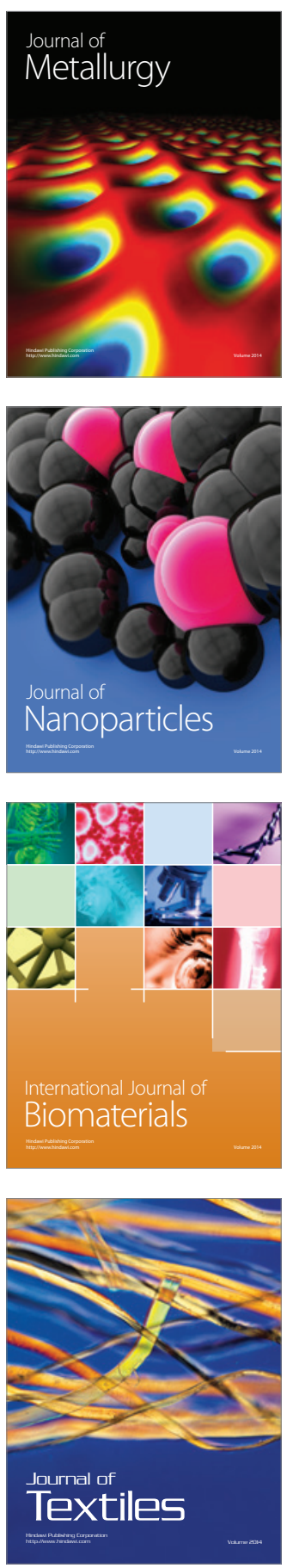